\title{
NACER MUDÉJAR Y MORIR MORISCO EN VALLADOLID. CONTRATIEMPOS AL CUMPLIMIENTO DEL DECRETO DE $1502^{1}$
}

\author{
Olatz Villanueva ZubizarReta ${ }^{2}$ \\ Universidad de Valladolid
}

Recibido: 7 de septiembre de 2018

Aceptado: 18 de diciembre de 2018

\section{Resumen}

En 1502 los Reyes Católicos dictaron la pragmática de conversión obligatoria a la fe católica que ponía fin a siglos de presencia de un Islam permitido y vivido en minoría (mudéjar) en la Corona de Castilla. Con él desaparecían un grupo social y religioso plenamente reconocido e integrado en la sociedad castellana, unas instituciones propias igualmente convenidas (aljama) y unos espacios de vecindad propios (morerías) con sus edificios religiosos. En este trabajo nos proponemos contribuir al conocimiento de este hecho histórico y de sus consecuencias a partir del análisis de lo sucedido en la ciudad de Valladolid, por disponer de documentación inédita novedosa que arroja información relevante sobre el tema.

\section{Palabras clave}

Islam. Mudéjares. Decreto de 1502. Mezquitas. Moriscos.

\begin{abstract}
In 1502 the Catholic Monarchs enacted the decree of compulsory conversion to the Catholic faith, a decree that put an end to the secular presence of an Islam that was allowed and lived in minority (as Mudejares) in the Crown of Castile. The decree meant the disappearance of a social and religious group fully recognised and assimilated in Castilian society, which had their own agreed-upon institutions (aljama), neighbourhoods (morería), and religious buildings. The present work purports to further our knowledge of this historical fact and of its consequences, by analysing what happened in the town of Valladolid, since we have new, unpublished documentation that provides significant information on this issue.
\end{abstract}

\section{Keywords}

Islam. Mudejares. Decree of 1502. Mosques. Moriscos.

\footnotetext{
Este trabajo se ha realizado con el apoyo del Proyecto I+D Excelencia "Estudio de los espacios rituales mudéjares en la Castilla medieval: Mezquitas y cementerios islámicos en una sociedad cristiana" del Ministerio de Ciencia, Innovación y Universidades (HAR2017-83004-P). Abreviaturas utilizadas: ACV (Archivo Catedralicio de Valladolid), AGS (Archivo General de Simancas), AMV (Archivo Municipal de Valladolid), ARChV (Archivo de la Real Chancillería de Valladolid).

2 Universidad de Valladolid. Correo electrónico: olatz.villanueva@uva.es. ORCID: https://orcid.org/00000002-6102-6891.
} 


\section{Resumé}

En 1502, les Rois Catholiques publient l'édit de conversion obligatoire à la foi catholique qui met un terme définitif dans le royaume de Castille à la présence d'un Islam toléré ayant un statut de minorité reconnue (mudéjare). De ce fait disparaissaient un groupe social et religieux pleinement reconnu et intégré à la société castillane, des institutions particulières également reconnues (les aljamas) et des espaces habités réservés (les morerías) avec leurs édifices religieux. Dans cet article, on se propose de contribuer à une meilleure connaissance de ce fait historique et de ses conséquences à partir de l'exemple de Valladolid, ville pour laquelle nous disposons d'une documentation inédite substantielle, qui apporte une vision novatrice sur le sujet.

\section{Mots-clés}

Islam, mudéjars, édit de 1502, mosquées, morisques.

\section{Introducción}

Valladolid contaba a finales de la Edad Media con una de las comunidades mudéjares más populosas de la Corona de Castilla. Las cantidades que pechaban en tributaciones especiales (el "servicio y medio servicio" y los "castellanos de oro") permiten calcular su población en esas fechas por encima del medio millar, la tercera en importancia numérica de la cuenca del Duero tras las de Ávila y Arévalo. La estimación coincide además con la relación de vecinos que se recogen en un padrón de 1506 elaborado para conocer sus identidades tras su conversión³.

Los importantes acontecimientos que tuvieron lugar en materia política y religiosa durante el reinado de los Reyes Católicos propiciaron que esta generación de musulmanes vallisoletanos viviera los últimos compases de su identidad islámica, que nacieran mudéjares y murieran moriscos. La pragmática del bautismo dictada en febrero de 1502 les obligó a abandonar sus prácticas islámicas que habían mantenido a lo largo de generaciones para inesperadamente aceptar, aprender y asimilar la fe cristiana mayoritaria ${ }^{4}$. El decreto supuso el final de la práctica islámica permitida durante siglos en la corona de Castilla. En el último decenio, y tras la expulsión de los judíos, la actitud ante los mudéjares que hasta entonces no había despertado hostilidad en la sociedad cristiana, tomó un nuevo rumbo. Se incrementó la presión fiscal hacia ellos y comenzó el deterioro de la convivencia, con amenazas veladas y rumores sobre su expulsión que los reyes intentaron silenciar mediante medidas que evidencian que la expulsión en esos años no entraba en sus planes. La situación empeoraría a partir de 1500 tras la sublevación en diciembre de 1499 de los mudéjares de Granada por el incumplimiento de las capitulaciones por parte de la Corona, y ante el temor a las represalias cristianas,

\footnotetext{
Moratinos García y Villanueva Zubizarreta, “Consecuencias del decreto de conversión al cristianismo", pp. 135-136.

4 El texto de la "Pragmática de expulsión de moros mayores de catorce años y moras mayores de doce años" dictada en Sevilla 12 de febrero de 1502, fue publicado por primera vez por FERNÁNDEZ y GONZÁLEZ, Estado social y político de los mudéjares de Castilla, pp. 432-434.
} 
los granadinos se convirtieron en masa en los meses siguientes. En Castilla, algunas aljamas solicitaron a los reyes cartas de protección ${ }^{5}$ y peticiones de carácter económico para satisfacer el pago de las cantidades exigidas en sus tributaciones específicas, ante la imposibilidad de hacerlo dadas las presiones crecientes. Finalmente, la corona terminaría aceptando una situación cada vez más insostenible, de forma que a finales de 1501 la decisión seguramente estaba tomada y se estudiaba ya la forma de culminar el proceso de unificación religiosa de la Corona de Castilla ${ }^{6}$.

La pragmática dictada el 12 de febrero de 1502 dio de plazo hasta finales de abril de ese año para que los mudéjares se bautizaran voluntariamente (o no) y fueran apadrinados por buenos cristianos.

Observar y analizar este hecho histórico es lo que nos proponemos en este trabajo. Y proponemos hacerlo a través de la presentación y análisis de los acontecimientos que tuvieron lugar en la villa de Valladolid durante los últimos años del siglo XV y primeros del XVI. Nueva documentación inédita permite ahora profundizar en la cuestión y conocer cómo se materializó el decreto en una de las aljamas más importantes de la Corona de Castilla?.

\section{La generación que vivió el bautismo en Valladolid: espacios y organización}

Como hemos dicho, a finales del siglo XV vivían en Valladolid algo más de medio millar de mudéjares, según los cálculos estimados a partir de su contribución en los pagos de los tributos del "servicio y medio servicio" de los años 1463 y 1464, en los que aportó 6.000 y 6.500 maravedís en uno y otro año, y de los 103 y 140 castellanos tributados durante la última década del siglo. Vivían en la morería situada al sur de la villa, en cumplimiento del decreto promulgado por la reina regente Catalina de Lancaster en 1412 que establecía la obligatoriedad de que los musulmanes del reino (igual que los judíos) vivieran apartados del resto de la población. Hasta entonces lo habían hecho dispersos por la villa, compartiendo espacios, y en ocasiones inmuebles, con sus convecinos cristianos y judíos.

Pero como decimos, en Valladolid aquella orden de reclusión se acató inmediatamente, a diferencia de otros lugares del reino en los que hubo que esperar a la orden de 1480 para conformar dichos barrios. Aquí, el cabildo de la iglesia colegial de Valladolid puso a disposición de las autoridades locales una huerta que tenía intramuros, a la par de la Puerta del Campo y tras las tapias del monasterio de San Francisco, para que los mudéjares pudieran

\footnotetext{
Ladero Quesada, Los mudéjares de Castilla en tiempos de Isabel I, pp. 17-20.

6 Sobre el contexto político y religioso de estos años, véanse, en particular, Ortego Rico, "Cristianos y mudéjares ante la conversión de 1502", pp. 280-284; TAPIA SÁncheZ, "1502 en Castilla La Vieja", pp. 135-136.

7 Quiero agradecer muy sinceramente a Julia Rodríguez de Diego, directora del Archivo General de Simancas, su colaboración en la búsqueda de la nueva documentación utilizada en este trabajo, y a mi colega de proyecto Luis Vasallo por su inestimable ayuda en la transcripción de la misma.

8 Ladero Quesada, Los mudéjares de Castilla en tiempos de Isabel I, pp. 17-20.
} 
urbanizar y levantar las edificaciones (particulares y de la comunidad) de su barrio moro. El contrato se firmó en enero de 1414 entre las partes: de una, los representantes de "la aljama e los omes buenos moros de ella", encabezada por el alfaquí Hamed, y, de la otra, el prior y el cabildo de la iglesia colegial. Acordaron arrendar la huerta a censo perpetuo a cambio de un pago único (de la comunidad, la aljama) de 40 florines de oro anuales 9 El solar, de planta triangular y de una superficie de algo más de dos hectáreas, se cercó, como obligaba la ley, con una muralla cuya única puerta de entrada se encontraba frente a las tapias del monasterio de San Francisco, entonces calle del Mercado. Su interior se urbanizó en torno a dos calles principales longitudinales y tres callejas perpendiculares que las atravesaban. Además de las viviendas que se fueron construyendo en la morería (sobrepasaban el centenar a finales de siglo), adosado al muro de la ronda se levantó un complejo de edificios destinados a la reunión y el rezo de la comunidad. Los documentos mencionan que en torno a un patio (con su pozo y arbolado) se construyeron la mezquita (el "almají"), unos inmuebles para disfrutar de las celebraciones ("la casa de bodas") y otros para alojar a desfavorecidos ("casillas para los pobres"), además de la casa del alfaquí y de la carnicería que se levantó adosada a ésta, aunque fuera del complejo.

Esta generación disponía además de dos lugares de enterramiento. Uno se encontraba al norte de la aglomeración, al que llamaban en esta época el "almocabyr viejo junto a San Pedro", por situarse junto a esa iglesia extramuros. Fue el utilizado desde tiempo inmemorial y permaneció en uso hasta las fechas mismas de la conversión de 1502, como lo atestigua el testamento del alcaller Ramiro Alcalde que dejaba escrita su voluntad de enterrarse allí junto a la tumba de su mujer ${ }^{10}$. Más tarde, a mediados del siglo XV, la aljama mora compró una tierra al sur de la villa, a las afueras de la Puerta del Campo, junto al camino que conducía a Simancas y divisable desde la morería, para usarlo como segundo cementerio. Seguramente, no fue debido a una masificación del existente ni a un incremento poblacional de su colectivo, sino que como consecuencia del traslado de los musulmanes a la morería, las autoridades locales o los propios miembros de la aljama vieron conveniente la utilización de otro osario para que los cortejos fúnebres no atravesaran toda la ciudad desde el nuevo barrio donde residía ahora toda la comunidad hasta el "almocabyr" situado al norte de la villa, el de San Pedro".

La última generación mudéjar, como lo venían haciendo las precedentes desde sus orígenes y lo siguieron haciendo en la etapa morisca, se dedicaban mayoritariamente a oficios relacionados con la construcción (carpinteros y yeseros, principalmente) y a la manufactura de productos cerámicos (vajilla doméstica y tejas), ocupaciones que prácticamente monopolizaban en la villa debido al reconocimiento de su buen hacer $\mathrm{y}$ a su tradición laboral ${ }^{12}$.

\footnotetext{
Moratinos García y Villanueva Zubizarreta, "Consecuencias del decreto de conversión al cristianismo", pp. 118-120.

10 Araus Ballesteros y Villanueva Zubizarreta, "La identidad musulmana de los mudéjares de la Cuenca del Duero", pp. 537.

11 Villanueva Zubizarreta, “Conflictos y arbitrajes en la morería de Valladolid”, pp. 104-105.

12 Villanueva Zubizarreta, "Vivir y convivir bajo la señal de la media luna”, pp. 27-30.
} 
Diversas y variadas evidencias (escritas y arqueológicas) acreditan el mantenimiento de la identidad musulmana por parte de los mudéjares vallisoletanos. Confirman la confesión de su fe islámica (a través de testimonios conservados de la "shahada" y de la "basmala", entre otros), la práctica de la oración en la mezquita, la aportación de la limosna para el bien colectivo, la celebración de las festividades del calendario musulmán y la peregrinación a La Meca ${ }^{13}$, como expresiones del cumplimiento de los cinco preceptos básicos del Islam ${ }^{14}$. La identidad social del colectivo también estaba patente a través de su agrupamiento y reconocimiento a través de la institución de la aljama, con cargos propios que garantizaban su funcionamiento interno y su representación ante las autoridades municipales y del reino. En la década de los 80, Brayme Aragonés ocupaba el cargo de alcalde y de alfaquí de la villa ${ }^{15}$; y más tarde, el toledano Abrahen Xarafi, que ostentando este mismo cargo, fue nombrado alcalde mayor de las aljamas del reino ${ }^{16}$. Estos moros, organizados en la aljama y vecinos de la morería, fueron los que vivieron el decreto de 1502, los que temieron por un futuro incierto y los que padecieron las consecuencias de la aplicación del mismo, y con él el final de su condición e identidad islámica.

\section{Lo acontecido en Valladolid en los años previos al decreto de 1502}

Para conocer el ambiente y el pulso de la vida urbana en esos años que precedieron al año del decreto, disponemos de dos fuentes principales, como son los protocolos notariales (el reflejo de la cotidianidad, pero de los que sólo se han conservado en Valladolid dos legajos) y, sobre todo, las actas del concejo ${ }^{17}$ que recogen la actividad de gobierno de la vida urbana, amén de los pleitos que puntualmente sostuvieron particulares e instituciones locales entre sí.

Durante el decenio previo a 1502 apenas se registran en la ciudad, ni entre los miembros de la aljama, actitudes o hechos que anunciaran el malestar creciente hacia la minoría mudéjar que pareció extenderse en aquellas fechas por todo el reino y que fueron el preludio de la decisión final tomada por los monarcas.

A principios de ese decenio, el concejo de Valladolid decidió acometer una importante obra de traída de agua a la ciudad desde la huerta de las Marinas. El proyecto fue encargado a un maestro moro de Guadalajara, pero los caños de barro que canalizarían el agua los concertaron en 1494 con diez alcalleres locales, todos ellos moros de la aljama

\footnotetext{
13 Casassas Canals et al., De Ávila a La Meca: el relato del viaje de Omar Patún (1491-1495).

14 Sobre este particular y el detalle de todas estas expresiones, remitimos a ViLlanueva ZubizarReta, "Los mudéjares del norte de Castilla en vísperas del bautismo", pp. 194-208.

15 RucQuoi, Valladolid en la Edad Media, p. 464.

16 MolÉnAt, “À propos d'Abrahen Xarafí: les alcaldes mayores de los moros de Castille”, pp. 175-184.

17 Valladolid ha conservado sus Libros de Actas desde 1497, siendo el primero el que recoge los acuerdos de los años 1497 a 1501. El estudio de los primeros libros ha sido objeto de una Tesis Doctoral por parte de Arenzana Antoñanzas, Los libros de Actas del Concejo de Valladolid. Agradezco muy sinceramente a su autor su generosidad a la hora de brindarme información aún inédita sobre el tema.
} 
de la ciudad, a los que el mayordomo de las obras pagó en $1497^{18}$. Aunque el proyecto fue incumplido por el maestro de la obra (maestre Yuza), el trabajo y la relación con los alcalleres se realizó conforme a lo fijado y no hubo ningún problema con su trabajo. En esos mismos años, entre 1494 y 1495, los miembros de la aljama sostuvieron un pleito con un destacado vecino de la villa, el regidor Pero Niño, aunque aquí a título particular o privado, por las desavenencias sobre la supuesta apropiación de éste de parte de las tierras del cementerio moro situado a las afueras de la Puerta del Campo. La aljama acusó a Niño de haber ocupado en esos años parte de su propiedad lindante con la tierra de aquél. La sentencia dio finalmente la razón a los moros frente a uno de los vecinos más poderosos de la villa, su regidor (aunque aquí, insistimos, a título particular), demostrando que la aljama no se amedrentó a la hora de defender sus derechos en algo tan substancial a su identidad religiosa como era uno de sus espacios funerarios y que las autoridades tampoco tuvieron reparos en darles la razón ${ }^{19}$.

Más allá de estos hechos puntuales, las actas del concejo de esa década no recogen desavenencias ni conflictos con la minoría mudéjar. Todos los ordenamientos y acuerdos anotados en ellas en relación a la aljama o a sus miembros de forma particular, no registran actuaciones que tuviesen que ver con un aparente cambio de rumbo en las relaciones de convivencia con la aljama que está a punto de desaparecer como tal. O eso se desprende del carácter de los asientos reflejados en sus actas. Nada del clima de preocupación y hostigamiento hacia la minoría que se registró en Castilla parece observarse de forma ostensible en las actas concejiles.

De la treintena de asientos (de un total de 769) que el primer Libro de Actas (14971501) tiene como protagonistas a moros, la mayoría de ellos hacen alusión a cuestiones que tienen que ver con el desempeño de actividades públicas por parte de los miembros de la aljama, como nombramientos de cargos (alarifes ${ }^{20}$, bomberos $^{21}, \ldots$ ), libranzas de

18 El libro del regimiento recoge el acuerdo de 12 de junio de 1497 que mandaba librar a "Francisco de Ribadeneyra mayordomo de las obras de dicho concejo a Caço Conde, e a maestre Homa e a Ramiro el Allcalde moros vecinos de esta villa siete mil mrs" "que... les quedo devyendo a los sobredichos e a Faray Allcalde e Hamed Pabad e Aly Alyasar e a Çubema Mejorado e a Brayme Huzmyn e a Caso Herrero e a Mahomad Yadel moros alcalleres asy mismo vezynos desta dicha villa"... "los quales son de mas de tres e mil quinientos mrs que se los ovyeron dado en cuenta de los dichos caños en veynte e dos días de setiembre del dicho año de noventa y quatro... que son todos los mrs que con los dichos moros se asentaron que se les ovyesen de dar por los dichos caños veynte mil e quinientos mrs". Apagito y Revilla, "Los abastecimientos de aguas de Valladolid", pp. 42-46.

19 Villanueva Zubizarreta, "Conflictos y arbitrajes en la morería de Valladolid", pp. 104-106.

20 El 20 de mayo de 1500 se nombró veedor de las obras de la villa a maestre Ali Andado, que juró en su ley, dándole poder para actuar en todo lo que en este oficio se debía hacer (AMV, Libro de Actas I, f. 284r-v). Sin embargo, el 7 de octubre se le retiró del cargo por ser yesero y no carpintero, mandando a dos regidores que en la siguiente sesión propusieran el nombre de un carpintero y que, curiosamente, fuera cristiano (AMV, Libro de Actas I, ff. 308r-v y 430r-v). Unas semanas más tarde, otro asiento restituía a Ali Andado en el oficio de alarife del que se le había privado por no llevar los niveles y otros aparejos para nivelar el agua de la huerta de las Marinas, cuando la inspeccionaron autoridades municipales (AMV, Libro de Actas I, ff. 312r y 433r-v).

21 Sin duda, el reconocimiento a la pericia de los moros en el campo de la construcción y el peligro constante de la villa a los incendios, motivó que el concejo contratara un servicio de extinción de fuegos 
$\operatorname{pagos}^{22}$ o contrataciones de trabajos ${ }^{23}$. Le siguen en número los que tienen que ver con requerimientos a los representantes de la aljama de la villa, para adecentar ciertas zonas de la ciudad que estaban próximas a la morería y que parece que tienen que ver con una habitual preocupación por la salubridad pública ${ }^{24}$. Y los menos recogen obligaciones y rentas de propiedades del concejo en manos de los mudéjares en esos años ${ }^{25}$.

y que éste recayera en ellos, a un precio de 3.000 maravedís anuales, al menos desde los últimos años del siglo XV, cuando existe constancia documental en las actas concejiles de exenciones y pagos a este colectivo. En 1497 se acordaba que pudieran comprar madera para sus casas y desde el año siguiente se registran pagos periódicos por su trabajo anual. Por lo allí apuntado sabemos que eran treinta "los moros obligados al fuego" y que cada uno aportaba su propia herramienta. VillanueVa ZubizarReta, "Los moros obligados al fuego", pp. 39-46.

22 Por ejemplo, en febrero de 1497 se libraron a Hame Sancho 510 maravedís por el derribo de quince tapias de una huerta que estaban en el camino de las Marinas, para nivelar el terreno de la obra que acometía el Concejo para llevar el agua a la villa (AMV, Libro de Actas I, f. 10v).

23 El protagonismo y reconocimiento profesional que los carpinteros adquirieron en la villa hizo que en ocasiones el concejo contratara sus servicios para el mantenimiento urbano de la villa o para la edificación y reparación de propiedades públicas, a veces los mismos "que están obligados al fuego". Esto ocurre en mayo de 1500 cuando se les requirió para derribar el balcón de la casa del doctor de Roenes, en la Plaza Vieja, "por estar en contra de la pragmática y mandamiento de Sus Altezas" o, en el mismo día, para derribar igualmente una obra nueva que se estaba haciendo sin licencia en la callejuela de los Vinagrosos, que "eran gran perjuicio para la villa por oscuridad y largura que tiene, y por ello se puede robar, asaltar, herir, matar y forzar a mujeres y mozas". Al tiempo, el corregidor y regidores mandaron inhabilitar a dos carpinteros del cargo de alarifes, por incumplir el juramento de comunicar al regimiento las obras que se hacían en la villa. En su lugar, nombraron el mismo día al maestre Ali moro (acaso aquel Ali Andado), instándole a que el primer día de regimiento se personara con otro carpintero cristiano para que "ambos juren su oficio con la solemnidad necesaria" (AMV, Libro de Actas I, ff. 282v-283v y 412rv). Al año siguiente, en abril, los moros fueron nuevamente requeridos para derribar los muros que el mercader Alonso de Medina había levantado en la trasera de su casa, en suelos concejiles (AMV, Libro de Actas I, ff. 467v-468r). Pero como decíamos, también fueron contratados para edificar obra pública; en octubre de aquel año, el maestre Ali proyectaba la construcción de la Casa de la Panadería, y los regidores enviaron a dos carpinteros a tasar el coste de las verjas y de la obra en general (AMV, Libro de Actas I, ff. $336 \mathrm{v}-337 \mathrm{r}$ y $448 \mathrm{v}-449 \mathrm{r})$.

24 En septiembre de 1498 obligaron a Zulema Castañón, Ali Andado "y a los regidores de la morería" a abandonar el muladar de la Puerta del Campo (en los límites del barrio) y a echar la basura donde les indicara el regidor Pero Niño, aquél con el que habían tenido años antes el conflicto por la ocupación de parte de su cementerio (AMV, Libro de Actas I, ff. 70v-71r) y, en diciembre de 1501, a adecentar (limpiar y empedrar) las calles situadas desde la morería hasta la puerta de Teresa Gil con ocasión del recibimiento que la ciudad haría a sus altezas (AMV, Libro de Actas I, ff. 347v-349r). Al año siguiente, en septiembre, el concejo comunicó a "Mahomad Muça, regidor, e a Farax de la Rua, mayordomo de la dicha aljama, e a Mastre Alí Andado, e a Mastre Çulema Mejorado, e a Mahomad Alcalde, e a Maestre Yaya Carretón, e a Mastre Mahomad Carretón" que tenían un plazo de mes y medio para reparar el muro de la morería en la parte de la ronda (AMV, Libro de Actas I, ff. 89r; 246r-v y 374r-375r).

25 En julio de 1499, los moros Carretón y Yuza de Medina registraban el pago correspondiente por el disfrute de los viñedos de los pagos de Perales, Argales y Las Marinejas, jurando las ordenanzas (AMV, Libro de Actas I, ff. 88v y 367v). Años más tarde, en enero de 1501, precisamente Aya Carretón conseguía licencia para vender y traspasar la heredad de Perales previo pago al concejo del censo de los 100 maravedís que la ribera tenía, cuando éste hiciera el nuevo contrato y quedaran incorporadas las condiciones de su traspaso al nuevo arrendador, Pedro de Bocos, camarero del condestable (AMV, Libro de Actas I, ff. 443r-v). 
Aparte de estas cuestiones, apenas un par de hechos podrían delatar cierto distanciamiento entre los miembros de la aljama y sus convecinos en fechas previas a dictarse el decreto de bautismo. El 1 de junio de 1500, el concejo prohibía a los moros y moras de cualquier edad salir de la morería el día del Corpus Christi, desde el comienzo hasta el final de la procesión, so pena de cincuenta azotes ${ }^{26}$. Pero sin duda, más esclarecedora sobre este particular resulta la noticia recogida en un asiento de diciembre de 1501 que informa de que (no sabemos cuándo) se había dado un pregón en la villa por el que se prohibía a los moros vender sus heredades ${ }^{27}$. Esta circunstancia parece coincidir con lo que estaba sucediendo en otras ciudades del reino, en especial de la cuenca del Duero, en las que sus vecinos moros encontraban igualmente serias dificultades a la hora de vender sus bienes para satisfacer el pago del impuesto de los "castellanos de oro" o hacer frente a gastos particulares, o por el temor ante un futuro inmediato nada halagüeño para la comunidad ${ }^{28}$. Seguramente, después de ese pregón, la incertidumbre y temor (como estaba sucediendo también en otros lugares) se extendió igualmente entre los miembros de la comunidad mudéjar de Valladolid y, tal vez por ello, la aljama se dirigiera a los monarcas en una fecha desconocida de aquellos años de 1500 ó 1501 pidiendo amparo e información ante los hechos que se estaban sucediendo y los rumores que circulaban, de lo cual no tenemos constancia documental. Sin embargo, sí tenemos constancia de la misiva que los reyes enviaron a la aljama de Valladolid una semana antes de publicarse el decreto de bautismo, y que confirma los temores y la solicitud de amparo trasmitida a los monarcas por parte de la aljama vallisoletana. Por lo que parece, la mayor preocupación de los vecinos moros era conocer si con su bautismo perderían sus posesiones en la morería, el espacio, las casas y los edificios de la comunidad que la aljama (como institución) había arrendado en 1414 al cabildo de la iglesia colegial. Los monarcas, como vemos en la carta del 6 de febrero de 1502 dirigida a la "aljama, alfaquíes, alguacil viejos, buenos hombres moros de la villa de Valladolid", les aseguraba que instaría al cabildo $\mathrm{y}$ al corregidor de la villa para que no perdieran su patrimonio.

"Nos somos informados que vosotros o alguno de vos tenéis buena voluntad de vos convertir a nuestra santa fe católica, de lo cual habemos habido mucho placer porque deseamos la salvación de vuestras ánimas y pues a nuestro Señor

\footnotetext{
26 AMV, Libro de Actas I, ff. 287r-v y 413r-v.

27 El asiento recoge que, ante las dificultades que Brahim don Juan tuvo para vender la heredad que disfrutaba a censo perpetuo del concejo, le otorgaban licencia para traspasarla por haberla puesto a la venta antes de que se diese el pregón, y que lo había hecho para pagar unas deudas que debía a ciertos vecinos, entre ellos, al procurador Francisco de Valladolid, a Brahim Xarafi y a Mahoma Alcalde (AMV, Libro de Actas I, ff. 346v-347r; 496v y 502r bis).

28 El caso de los moros de la villa de Aranda de Duero, maestre Abdalla y maestre Ydan, resulta esclarecedor acerca de los rumores que circulaban por esas fechas en el reino: "no ay persona que los ose nin quiera conprar [los bienes] diziendo que nos [los reyes] tenemos por bien que los moros moradores en estos nuestros Reynos, nuestros súbditos sean expulsos e echados d'ellos, e que a esta cabsa se teme de comprar los dichos bienes diziendo que como nos mandamos echar las personas que tanbién querremos tomar sus bienes". ORTEGo Rico, “Cristianos y mudéjares ante la conversión de 1502”, p. 283.
} 
plugo que los moros del reino de Granada que eran en tanta cantidad como sabéis e nacidos e criados e envejecidos en aquel yerro e más apartados de la conversación de los cristianos, se convirtiesen a nuestra santa fe católica. Deseamos que así lo hagáis vosotros pues habéis tenido tanta continua conversación de los cristianos e vos es más cercano el conocimiento de nuestra fe católica. Por ende nos vos rogamos que queráis poner en obra de vos convertir, certificando vos que allende del servicio que en ello haréis a nuestro Señor y bien y provecho a vuestras ánimas, nos haréis mucho placer e haciéndolo así vos mandaremos honrar e mirar por vosotros e por las cosas que os tocaren de muy buena voluntad. E porque así mismo habemos sabido que dilatáis la dicha conversión a causa de vuestras casas que tenéis a censo de la iglesia colegial e del abad de Valladolid, diciendo que está puesta condición que si os tornáredes cristianos vuelvan las dichas casas a la dicha iglesia. Nos escribimos al abad prior y canónigos e cabildo de la dicha iglesia que si tal condición hay la den luego por ninguna e así mismo al corregidor de esa misma villa que solicite ser ciertos que se hará así y que por aquella condición no seréis sacados de vuestras casas e que las ternéis como hasta aquí las teníades. De la ciudad de Sevilla a 6 días del mes de febrero de 1502, yo el rey, yo la reina" ${ }^{29}$.

Probablemente cuando los moros de Valladolid conocieron la respuesta real a sus demandas, la orden del bautismo ya estaba dictada y pregonada por las ciudades del reino. En ella se instaba a la conversión obligatoria de todos los moros varones mayores de catorce años y mujeres mayores de doce ${ }^{30}$. Se fijó un plazo de dos meses para que fuesen bautizados, de forma que en abril de 1502 los moros castellanos se convirtieron a la fe católica, algunos voluntariamente y la mayoría contra su voluntad ${ }^{31}$.

\section{El cumplimiento y las repercusiones del decreto de 1502 en Valladolid}

Tenemos poca información de lo que sucedió en Valladolid en la primavera de aquel año y de cómo se realizaron los bautismos de los mudéjares. Como ocurrió en otros lugares, probablemente fueron apadrinados por vecinos cristianos, pertenecientes o no a la élite social, pero sin que conozcamos sus identidades ni los detalles de las ceremonias. En ellas se les impuso un nombre cristiano que vino a sustituir al patronímico que habían mantenido durante generaciones, compuesto en su mayoría por el "ism" arábigo seguido de un apellido que respondía a la forma castellanizada del "nasab", el "nisba" o el "laqab"

\footnotetext{
29 A.R.Ch.V, Sección de Pleitos Civiles (fenecidos), Zarandona y Balboa, C-159/1.

30 Ladero Quesada, Los mudéjares de Castilla, pp. 127-130.

31 Así lo recoge la crónica de Andrés Bernáldez en sus Memorias del reinado de los Reyes Católicos. Tapia SÁnchez, "1502 en Castilla La Vieja”, p. 134. Ver también Ortego Rico, "Cristianos y mudéjares ante la conversión de 1502”.

32 Araus Ballesteros y Villanueva Zubizarreta, "La identidad musulmana de los mudéjares de la Cuenca del Duero", pp. 531-532.
} 
En su mayoría, mantuvieron su apellido y cambiaron el nombre de pila por uno cristiano. Sabemos que Farax Alcalde pasó a llamarse Diego Alcalde; su hermano Mahomad, Bernaldo de León; Arleme Castaño, Luis Castaño; o Farax de la Rua, Juan de la Rua. En algunos casos, los bautizados cambiaron también sus apellidos (maestre Ali pasaría a llamarse Francisco Hernández de Palacios o Hamed Sancho, Sancho de Mendoza), acaso adoptando el apelativo de sus padrinos, cuya identidad, como decimos, se desconoce.

Los temores que los moros vallisoletanos habían manifestado meses antes a los monarcas acerca de si su bautismo les acarrearía la pérdida de sus posesiones en la morería, se cumplieron. Pero no fue, como sospechaban sus vecinos, la iglesia colegial como propietaria del suelo del barrio quien primero se incautaría de sus propiedades, sino que fue la propia Corona quien tomó para sí los bienes colectivos de las comunidades mudéjares, por entender que al desaparecer la aljama como institución jurídica, sus posesiones pasaban a sus dominios. En los meses siguientes, la reina Isabel, como propietaria de estos suelos y edificios, y de sus materiales (piedra, madera, teja), procedió a su donación o a su venta a demanda de particulares y concejos.

En el caso de Valladolid, un año después del decreto, el 2 de marzo de 1503, la reina donaba la mitad de la mezquita, de los cementerios y sus terrenos, de la carnicería y de la casa del alfaquí de la antigua morería al licenciado Juan de Pedrosa, y la otra mitad a doña Mencía de Ayala, en recompensa a ambos por los servicios prestados. La cédula otorgada a su dama detalla la donación.

"La reyna por faser bien e merçed a vos Doña Mençía de Ayala acatando los muchos e buenos seruiçios que me avéys fecho e faséys de cada día por la presente vos fago merçed gracia, donaçión pura e perfeta e no reuocable que es dicha entre bibos para agora e para syenpre jamás de la mitad de la mezquita e honsarios con las tierras e piedra a ellos pertenesçientes e de las casas del alfaquí e de boda e carneçería e de todos los otros bienes muebles e raýses e çensos e otras qualesquier cosas e mrs comunes que en qualquier manera los que heran moros vecinos de la villa de Valladolid que agora son convertidos a nuestra santa fee católica tenían en la dicha villa e su tierra con todas sus entradas e salidas, fueros, vsos e costumbres quantas han e aver deven e les pertenesçen en qualquier manera para que sea la mitad de todo ello vuestro e de vuestros herederos e subçesores e de aquel o aquellos que de vos o dellos oviere týtulo o cabsa o rasón e para que la podades e puedan dar trocar e cambiar e henajenar e faser dello e en ello todo lo que quisyeredes e por bien tovieredes como de cosa vuestra propia e avida por justo e derecho týtulo e mando a los alcaldes de la mi abdiençia de Valladolid e a los regidores e alcaldes e otros jueses de la dicha villa e a qualquier dellos que luego que con esta mi çédula fueren requeridos syn dilaçión alguna vos pongan en la posesión de la mitad de todo lo susodicho e que vos anparen e defiendan en ella e que no consientan ni den lugar que della seáys despojada agora ni en algund tiempo ni por 
alguna manera syn ser primeramente oýda e vençiada por fuero e por derecho ante quien e como deváys la qual dicha merçed vos fago con tanto que seáys obligada a pagar por renta qualquier sytuado que qualesquier personas tengan sobre el aljama de los que heran moros vecinos de la dicha villa. E los vnos ni los otros no fagades ende al por alguna manera so pena de la mi merçed e de dies mill mrs para la mi cámara. Fecha en la villa de Alcalá de Henares a dos días del mes de março de quinientos e tres años. Yo la Reyna" ${ }^{3}$

Con esta donación, la reina quiso distinguir a dos miembros de su entorno más próximo. Juan de Pedrosa (o Juan González de Pedrosa) fue un letrado formado en Salamanca y becado en el Colegio del cardenal Mendoza de Valladolid, que fue nombrado en 1492 oidor del Consejo Real. Meses después de que la reina le hiciera donación de los bienes de la aljama vallisoletana, los monarcas le destinaron como embajador en Roma y más tarde, Fernando le encargó que se ocupara de los asuntos de Estado y Hacienda en Nápoles, donde murió hacia 1510.

Por su parte, Mencía de Ayala era hija de García López de Ayala (señor de la casa de Ayala) y de María de Sarmiento, y estuvo vinculada a Valladolid tras la compra por parte de su madre de unas casas en la calle de San Martín. Fue la esposa de Antonio de Fonseca, IV señor de Coca y Alaejos, que desempeñó múltiples e importantes cargos en la corte, entre otros el de Comendador Mayor de Castilla, miembro del Consejo Real o testamentario de la reina Isabel. A ella la tuvo como dama en su Casa al menos entre los años 1500 y 1504, cobrando 40.000 maravedís anuales, de forma que cuando la reina le hizo la donación, estaba a su servicio ${ }^{34}$.

Semanas después de que la reina donara los bienes de la aljama, el 27 de abril, Juan de Montalvo, criado de Mencía de Ayala, tomaba posesión en su nombre de los bienes recibidos.

"estando dentro en la mesquita de los moros que ya heran convertidos de la fe en la dicha dicha villa de Valladolid estando ende present Alonso Gutiéres logarteniente del dicho alguasyl mayor paresçió y present el dicho Juan de Montalvo en el dicho nombre de la dicha Doña Mençía e dixo que pedía e requería al dicho alguasyl que le pusiese en la posesión de la mitad de la dicha mesquita segund que en la dicha çédula e mandamiento se contenía e luego el dicho alguasyl tomó por la mano al dicho Juan de Montalvo en el dicho nombre e andovo paseándose dentro con él por la dicha mesquita e dixo que le ponía e puso en la posesión de la dicha mitad della, asý de lo alto como de lo baxo como mejor podía e de derecho debía e que mandava e mandó que la tomase e aprehendiese abtual e corporalmente e de palabra e por menudo en obra el dicho Juan de Montalvo en el dicho nombre en presencia de mí

\footnotetext{
33 A.C.V, Caja 130, 2. Sin foliar.

34 GonzÁlez Marrero, "Las mujeres de la Casa de Isabel la Católica”, p. 879.
} 
el dicho escriuano e de los testigos de yuso escritos andovo por la mitad de la dicha mezquita e la poseyó e echó fuera a todos los que ende estábamos e tomó la posesyón, ansý e la dicha mitad de mesquita como de la mytad de la casa de la boda e del alfaquí contenido en la dicha çédula porque todo es e está dentro de la dicha mesquita e andovo por todo paseando e hollandolo por sus pies en señal de posesión e çerró e abrió las puertas de la dicha mesquita en el dicho nombre e quedó e fincó por verdadero poseedor en la posesión (...) E después desto luego (...) fuemos a la casa de la carneçería de la dicha morería e entramos en ella e el dicho alguasyl le puso al dicho Juan de Montalvo en el dicho nombre en la posesión de la media della...

E después desto (...) fuimos al fonsario de los moros que heran de la dicha villa que es fuera de la villa a la Puerta del Campo e entramos dentro dél e el dicho alguasyl tomó por la mano al dicho Juan de Montalvo en el dicho nombre e andovo por el dicho honsario e por vna tierra questá junto cabél fuera de lo çercado hollándolo todo con sus pies e cortando yerbas de la dicha tierra en señal de posesión e abriendo e çerrando las puertas del dicho honsario aprehendió e tomó la posesión de la mitad dél e de la dicha tierra $<$ e piedras que en él estavan $>(\ldots)$

E después desto (...) estando dentro del otro honsario e huerta de los dichos moros que es la puerta de San Pedro cabe el río d'Esgueva de la dicha villa el dicho alguasyl poniendo en efeto lo contenido en la dicha çédula e mandamiento tomó por la mano al dicho Juan de Montalvo en el dicho nombre e andovo por el dicho honsario e casa e huerta pasándole con sus pies de vna parte a otra e de otra a otra tomando piedras e arrancando yerbas en señal de posesyón e esto asý fecho el dicho Juan de Montalvo abrió las puertas de las dichas casas e las çerró e eso mismo del dicho honsario e echó fuera a los que ende estávamos e lo andovo todo otra ves e aprehendió la posesión de la mitad de todo ello e de las piedras que en ello estavan (...)" ${ }^{\prime 35}$.

Al tiempo que el criado de Mencía de Ayala tomaba posesión de los bienes, se presentaba ante el alcalde de Corte y Chancillería un canónigo de la colegiata que trasmitía la oposición del cabildo a dicha toma de posesión. Alegaba que la parte de la colegiata no fue citada al acto y que, en cualquier caso, y pese a la acción real, las posesiones donadas y todo lo edificado en la antigua morería eran de su propiedad, ya que cuando se arrendó el barrio a los moros se puso como condición que si tornaban cristianos, el suelo con todo lo edificado volvería a dicha iglesia ${ }^{36}$.

Este desacuerdo entre las partes derivó en un pleito que enfrentó al cabildo de la colegiata con los beneficiarios de la donación real. Probablemente el litigio comenzó aquel mismo año de 1503 pero la documentación conservada data del año siguiente. En febrero

\footnotetext{
35 A.C.V, Caja 130, 2. Sin foliar.

36 Ibidem.
} 
de 1504, los reyes informaban al licenciado Aguirre, miembro de su Consejo, que en una cédula remitida al corregidor de la villa de Valladolid le ordenaban que la causa fuese vista en esa instancia; recordemos que tanto Pedrosa como el marido de Mencía de Ayala, Antonio de Fonseca, pertenecían a dicho consejo.

"que nos mandamos dar e dimos una nuestra çédula firmada de nuestros nombres e librada de los nuestros contadores mayores por la qual ynbiamos mandar al nuestro corregidor de la dicha villa de Valladolid. o a su lugarteniente en el dicho ofiçio que llamada la parte de las personas a quien ovimos fecho e fesimos merçed de los bienes comunes que tenían los moros de la dicha villa antes que se convertiesen a nuestra santa fee católica oviese ynformaçión quánto preçio e quantía de mrs. valen en la dicha villa cada millar de juro, fisesen pagar de los dichos bienes comunes al cura e capellanes de la yglesia de nuestra señora Santa María de la Antigua de la dicha villa dos mill mrs. de juro que tenían situados en la cabezça del pecho de los dichos moros, según que más largamente en la dicha nuestra çédula se contiene, e agora sabed que por parte de algunas de las personas a quien hezimos merçed de los dichos bienes nos fue fecha rrelaçión desyendo que ellos tienen por sospechoso al dicho nuestro corregidor e al dicho su lugarteniente, e por su parte nos fue suplicado e pedido por merçed nuestra diésemos cometer lo susodicho a una buena persona syn sospecha para que lo viese e determinase conforme a lo contenido en la dicha nuestra çédula. E como la nuestra merçed fuese e nos tovímoslo por bien porque vos mandes e veades la dicha nuestra çédula que de suso se haze mençión e la guardedes e cumplades e fagades guardar e complir en todo e por todo según que en ella se contiene e declara" ${ }^{37}$.

Meses más tarde, en junio, se dirigieron a los representantes del cabildo para informarles sobre los plazos y forma para presentar las probanzas ${ }^{38}$, de igual forma que lo harían a la otra parte, ante lo que, dos meses después, Mencía de Ayala solicitaría una prórroga que le fue aceptada ${ }^{39}$. A principios de septiembre, reclamaban igualmente información sobre los moriscos para incorporarla a la causa; en concreto,

"los traslados de los padrones de los rrepartimientos que los moros que agora son christianos tenían de algunos años pasados, de como solían rrepartyr la paga que fasyan a la dicha yglesia ... y nos suplicava e pedía pareçer sobre ello les provesyesemos de ... justiçia mandándole dar nuestra carta para vos, la dicha nuestra justiçia, para que apremiasedes a los dichos cristianos nuevos exibieran los traslados de los dichos rregistros de algunos años pasados de

\footnotetext{
AGS, RGS, 150402, 47, 13 de febrero de 1504, f. 1 r-v.

AGS, RGS, 150406, 31, 10 de junio de 1504, ff. 1-4.

AGS, RGS 150408, 179, 8 de agosto de 1504, f. 1 r-v.
} 
cómo rrepartyan los florines que solían e suelen pagar a la dicha yglesia para los presentar para guarda de su derecho o como la nuestra merçed fuese" ${ }^{40}$.

Mientras este contencioso se resolvía, el cabildo inició otro litigio con los moriscos, quienes vieron nuevamente cómo sus sospechas de que su condición morisca les acarrearía la pérdida de sus moradas se cumplían otra vez. El cabildo, como propietario y arrendador del suelo de la morería, entendió que las condiciones del censo firmado en 1414 quedaban obsoletas al no existir ya una minoría musulmana obligada a vivir apartadamente. Y entendía también que si los moriscos querían seguir viviendo en el barrio (ahora denominado de Santa María) debían de renegociar las condiciones del arriendo, pasando de un pago único (aquellos 40 florines anuales que pagaba la aljama en representación de la comunidad) a uno individual, de cada propietario. Ante el dispar punto de vista de las partes, el litigio se inició el 12 de diciembre de 1505 y se alargó durante tres décadas, en las cuales se sucedieron citaciones por ambas partes para la presentación de pruebas y testimonios que apoyaran y reforzaran sus respectivos pareceres. Durante el primer semestre del año 1506 ambas partes iniciaron el proceso nombrando a los procuradores que les representarían en la causa y presentando los primeros alegatos y posiciones sobre el objeto de la disputa: las nuevas condiciones de arriendo del barrio de Santa María que pretendía imponer el cabildo a sus moradores. Pero curiosamente, el 13 de septiembre, el procurador de los moriscos introducía una nueva causa en el litigio, muy interesante, como era el derribo y desmantelamiento por parte del cabildo de "las casas y corral del almají, las casas que fueron de bodas, además de otras casas" Seguramente, el derribo de los edificios que componían el complejo de la mezquita se debió de producir en los primeros días del mes de septiembre de aquel 1506, después de iniciarse el litigio entre ambas partes; y creemos que esto pudo ser así porque el último día del mes de agosto, el representante de la iglesia tomaba posesión de "las casas almají, bodas e carnecería", todavía en pie.

"Sepan cuantos esta carta de posesión vieren como en la muy noble y leal villa de Valladolid, lunes treinta y un días del mes de agosto año del nacimiento de Cristo Salvador (...) y de mil quinientos seis años, estando a las puertas de la mezquita y casa de bodas que solía ser de la morería y estando (...) de la una parte el bachiller Juan de Cantos de la iglesia colegial de Santa María la Mayor de esta dicha villa, como representante del prior y cabildo y del teniente de merino de la villa y en presencia del escribano y notario público del número de la villa y de la iglesia colegial, dio la posesión al bachiller de la mezquita, casa de bodas y carnecería de la antigua morería"42.

\footnotetext{
40 AGS, RGS, 150409, 472, 7 de septiembre de 1504, f. 1 r-v.

41 ARChV. Pleitos Civiles, Zarandona y Balboa (F). Caja 159.0001. Moratinos García y Villanueva Zubizarreta, "Consecuencias del decreto de conversión al cristianismo", p. 122.

42 ARChV. Pleitos Civiles, Zarandona y Balboa (F). Caja 159.0001, f. 181.
} 
La explicación a este hecho tiene que ver con la resolución del conflicto paralelo que había enfrentado al cabildo con el licenciado Pedrosa y Mencía de Ayala. El 26 de agosto, el fallo del Consejo Real había dado la razón a la institución eclesial ante la exposición y pruebas que había presentado en la causa:

"que podía aver noventa años poco más o menos que la dicha yglesia avía dado a çenso perpetuo a los moros e aljama de la dicha villa los dichos suelos por quarenta florines de censo, con condiçión que los dichos moros no lo pudiesen vender ni enagenar ni trocar ni cambiar ni nombrar para execuçiones ni debdas algunas... sy no fuese moro de la dicha morería, e syno que por el mismo caso se torne toda la dicha morería con lo en ella hedeficado e mejorado a la dicha yglesia, e con condiçión que sy en algund tiempo viniese la dicha morería que en ella no oviese tantos moros que se pudiese llamar aljama que por el mismo caso todos los hedefiçios que estoviesen en los dichos suelos hedeficados se tornasen a la dicha yglesia, e que usando del contrario sobre lo fecho la dicha morería que agora se llama barrio de Santa María hera de la dicha yglesia e le pertenecía e que podía entrar la dicha yglesia en la posesyón de todo lo que los dichos suelos hedeficado e mejorado. E quel señor rey don Fernando, nuestro padre, e la señora reyna doña Ysabel, nuestra madre, que está en gloria, vyan enbiaron mandar a la dicha yglesia al tiempo que los vecinos de la dicha morería se avían tornado a nuestra santa fee católica que les dexasen las dichas casas, e que por ser cosa piadosa e porque no fuesen de peor condiçión, tornandose cristianos que el dicho prior y cabildo lo avían avido por bien"43.

Por ello, y porque la otra parte no había presentado suficientes pruebas, se resolvía a favor del cabildo de la iglesia colegial de Valladolid.

"fallamos que el dicho deán e cabildo de la dicha yglesia mayor desta villa de Valladolid provaron bien e cumplidamente su yntençión e demanda, e aquello que provar les convenía para aver bitoria en esta cabsa, e que la dicha doña Mençía de Ayala ni el liçençiado Pedrosa ni sus herederos no provaron sus exebçiones e defensyones ni cosa alguna que les aprovechase, porque de que devemos dar e damos la yntençión del dicho deán e cabildo de la dicha yglesia por bien provada e la de los dichos doña Mençía de Ayala e liçençiado Pedrosa e sus herederos por no provada, e que devemos declarar e declaramos que la merçed que se fiso a la dicha doña Mençía de Ayala e liçençiado Pedrosa de la mezquita e casas e bodas e carneçerías questan en la morería e suelos della de la dicha villa de Valladolid que no ovo ni ha logar de derecho, e que

43 AGS, RGS, 150608, 35, 26 de agosto de 1506, f. 1 r-v. 
devemos mandar anparar de... en todo ello al dicho deán e cabildo de la dicha yglesia mayor para que lo tengan e posean... syn embargo de la dicha merçed que asy fue fecha a la dicha doña Mençía de Ayala e liçençiado Pedrosa. E por algunas cabsas e rrasones que a ello nos mueven no asemos condenaçión de costas a las partes, mas que cada una dellas se pare a las que fiso e por esta nuestra sentençia definiytva" ${ }^{\prime 4}$.

Así las cosas, con la propiedad del complejo religioso mudéjar nuevamente en manos del cabildo, éste debió decidir su desmantelamiento a lo largo de los primeros días del mes de septiembre de aquel 1506 considerando que ya no tenía lugar la existencia de unos edificios pertenecientes a una religión prohibida (en el caso de la mezquita y la casa de bodas) y a una institución (aljama) obsoleta (la casa del alfaquí y la carnicería). Sin embargo, y pese a estar construidos en suelo de propiedad ajena, para los moriscos los inmuebles constituían un legado de especial significación para el colectivo y su derribo un ultraje, más por su valor simbólico que por su valor económico. Según un testigo, los hechos se produjeron de noche,
"e ante las dichas casas y meschita quebrantaron las puertas y cerraduras de ellas, y derribaron la dicha meschita e casas e tomaron e llevaron toda la teja y madera de ellas y lo llevaron a sus casas e hicieron de ello lo que quisieron y entraron y llevaron todo lo que en la dicha casa hallaron (...)" ${ }^{\prime 45}$.

Desde esas fechas, la disputa entre las partes derivó en dos causas. Una tenía por objeto consensuar los términos del arrendamiento del barrio de Santa María; mantener el pago único y global según lo establecido en tiempos en que era morería, como opinaban los moriscos, o redactar un contrato individual de cada propiedad con su morador, como sostenía el cabildo. Y la otra se centraba en el derribo y desmantelamiento de la mezquita y edificios anexos del complejo, sobre lo cual los moriscos solicitaban ser indemnizados. Tras largos años de presentación de pruebas (entre ellas, un padrón de los vecinos en 1506) y de testimonios por parte de los testigos que eran requeridos y arrojaban información excepcional para conocer los últimos compases de la vida mudéjar en Valladolid (entre ellos, descripciones de la mezquita) ${ }^{46}$, el presidente y los oidores de la Chancillería dictaron sentencia en 1537. En lo referente a la primera cuestión, fallaron a favor del prior y el cabildo de la iglesia colegial, obligando a los moradores del barrio a aceptar un nuevo contrato individual por las propiedades que tenían arrendadas, para lo cual se redactó en 1538 un censo que contenía los contratos individuales suscritos por cada propiedad, firmados ante el escribano de la Iglesia de Santa María, y figurando en ellos

\footnotetext{
44 Ibidem, f. 3-4.

45 ARChV. Pleitos Civiles, Zarandona y Balboa (F). Caja 159.0001, f. 218.

46 Moratinos García y Villanueva Zubizarreta, "Consecuencias del decreto de conversión al cristianismo", pp. 120-129.
} 
los datos del titular (identidad y oficio) y la propiedad en cuestión con alusión a su localización y linderos ${ }^{47}$. Por el contrario, en lo que respecta a la causa iniciada por el derribo y desmantelamiento de los lugares de culto y reunión de la antigua morería, la Chancillería falló a favor de los moriscos, obligando al cabildo a pagar el valor de la madera sustraída de la mezquita y casa de bodas ${ }^{48}$.

Con la sentencia se culminaba un largo proceso que ponía punto y final a cualquier posible demanda sobre la cuestión por parte de ambas partes, pero, de alguna forma, también suponía el final de una etapa (la mudéjar) y el inicio de otra (la morisca) que se había iniciado con la publicación del decreto de bautismo de 1502.

\section{Epílogo}

Como consecuencia de estas actuaciones, se ponía fin a una forma de vivir el islam en minoría, consentida conforme a unas normas y ordenamientos dictados por la mayoría cristiana, pero que permitió a los mudéjares el mantenimiento de su identidad islámica hasta el final de la Edad Media. A partir de entonces, su condición de cristianos nuevos les otorgaría un estatus nuevo, con los mismos derechos y obligaciones que el resto de sus convecinos, al menos teóricamente. Aquellos primeros moriscos que habían nacido mudéjares tuvieron que asimilar prontamente que ya no estarían amparados por una institución propia (la aljama), que ya no estarían obligados a vivir apartadamente ni a llevar distintivos propios, ni que tenían derecho (ni sentido) ya a mantener sus antiguos lugares de culto (de reunión, rezo o enterramiento) porque el Islam estaba prohibido en el reino y por tanto no podían ser musulmanes, al menos pública y manifiestamente.

De los hechos narrados se desprende que en los años previos a 1502 los mudéjares vallisoletanos vivieron con incertidumbre los rumores que circularon en el reino sobre la amenaza de que se prohibiera su profesión de fe islámica. Probablemente ello preocupaba a los miembros de la aljama, pero lo que manifestaron públicamente, y por lo que pidieron explicaciones e intervención a los reyes, fue por el temor a que fueran desalojados de sus moradas. Mientras, y hasta esa fecha, aparentemente su vida social y profesional continuó como lo venían haciendo, o al menos eso se desprende de la documentación conservada. Las actas concejiles no registran conflictos con la minoría, ni un distanciamiento con sus miembros en el marco de las relaciones de vecindad; es más, desde el concejo siguieron recurriendo a su pericia y cualificación profesional para acometer obras de mantenimiento y construcción en la ciudad.

Las circunstancias que siguieron al cumplimiento del decreto siguen poniendo de manifiesto la preocupación de los moriscos por su futuro. Durante los meses siguientes no ha quedado constancia en las fuentes de su actitud hacia el cumplimiento de la orden de conversión obligatoria: si hubo peticiones o reclamaciones por la pérdida de su identidad islámica, y si aceptaron de buen grado o no las ceremonias de bautismo y el

\footnotetext{
47 Ibidem, pp, 137-138.

48 Ibidem, pp, 128-129.
} 
cambio de su onomástica. Imaginamos que en el seno del grupo hubo incertidumbre, malestar y añoranza por la pérdida de su condición e identidad islámicas, pero nada de ello se reflejó en las fuentes ni en la actitud del resto de la sociedad vallisoletana. Los documentos no registran en esos meses incidentes ni disturbios entre los moriscos y sus convecinos.

Aceptada públicamente su nueva condición de cristianos nuevos, tomaron partido activo en las decisiones que las instituciones reales y locales tenían para sus posesiones en el barrio, ahora de Santa María. Inicialmente, manteniéndose al margen del conflicto por la posesión del complejo religioso de la morería que enfrentó a los beneficiarios de la donación real (el licenciado Juan de Pedrosa y su dama Mencía de Ayala) y al propietario del suelo (el cabildo de la iglesia colegial). Pero, más tarde, tomaron parte activa y pleitearon con el cabildo sobre los derechos y condiciones del arriendo de sus moradas, y al poco, ya desde septiembre de 1506, por el derribo de los edificios de su complejo religioso. En ambos casos, la preocupación y reivindicación del colectivo (que seguían cohesionados, aunque ya no como aljama sino como vecinos del barrio de Santa María) giraba en torno a asegurar las mejores condiciones del arriendo de sus viviendas, por un lado, y a recibir una compensación económica por el desmantelamiento del complejo de la mezquita, por otro. Al margen de esta manifiesta preocupación económica plasmada documentalmente en ambas causas, nada sabemos del sentir de estos vecinos por la pérdida de tan emblemáticos edificios que simbolizaban la expresión religiosa y cultural de una fe que les fue prohibida súbitamente.

Imaginamos que el proceso de asimilación a su nueva condición cristiana tuvo que resultar difícil, sobre todo para esta generación nacida mudéjar, que vivió estos acontecimientos vitales seguramente con resignación y aceptación. Algunos testimonios de la época podrían indicar las dificultades en asimilar y aceptar su nuevo estatus social y religioso. Algunas familias, como los Palacios, seguían recurriendo a la tradición y derecho islámicos para establecer sus relaciones y repartir sus herencias ${ }^{49}$. Otros, recibían sentencias de excomunión y encarcelamiento, probablemente por desviaciones en su conducta religiosa, no aceptada o todavía no asimilada ${ }^{50}$. Pero más allá de estas actitudes particulares y privadas con reminiscencias del pasado, el colectivo morisco también manifestó desde estas mismas fechas su voluntad por seguir participando en la vida profesional de la villa, de forma individual, pero también en grupo, como por ejemplo en el servicio encargado de atajar los incendios. Igualmente, les interesó participar en el pulso político de la villa, significándose, por ejemplo en las décadas previas

\footnotetext{
49 Araus Ballesteros, "En tiempo en que todos ellos heran moros", pp. 414-419.

50 En 1524 Diego Ramírez sostuvo junto a los también vecinos del barrio de Santa María, Alejandro Carretón, Juan de Malpartida, Juan el Vicario y Francisco de Herrero un pleito con el cabildo por una sentencia de excomunión y encarcelamiento en su contra. El pago de una fianza le permitió ser excarcelado, pero no librarse de la multa de 600 maravedís que le impusieron. Villanueva Zubizarreta, "Conflictos y arbitrajes en la morería de Valladolid", pp. 112.
} 
a la Revuelta Comunera, en el conflicto que enfrentó al común con el regimiento de la villa por tener representación en el gobierno local ${ }^{51}$.

En definitiva, en estos primeros compases de la nueva vida morisca, se muestra a un colectivo inevitablemente aún cohesionado por una identidad repentinamente arrebatada, que reivindicaba derechos, espacios y edificios de su pasado común, pero que a la vez intentaba adaptarse a la nueva realidad social y sumarse a la vida de sus convecinos, ahora que sus derechos y obligaciones se habían equiparado a los de ellos. El estudio de la actitud de las siguientes generaciones de moriscos y de su devenir durante todo el siglo XVI permitirá conocer hasta qué punto mantuvieron o no en las siguientes generaciones unas prácticas criptomusulmanas que justificarían, como lo hicieron, la definitiva expulsión de los moriscos en 1609 por parte de Felipe III.

\section{Bibliografía}

Agapito y Revilla, Juan, "Los abastecimientos de aguas de Valladolid. Apuntes históricos", Boletín de la Sociedad Castellana de Excursiones (1907-1908) III, (1984), pp. 41-67.

Araus Ballesteros, Luis, "En tiempo en que todos ellos heran moros. Pervivencias islámicas en una familia morisca de Castilla la Vieja”, Actas XIII Simposio Internacional de Mudejarismo, Centro de Estudios Mudéjares, Teruel, 2017, pp. 405-425.

Araus Ballesteros, Luis y Villanueva Zubizarreta, Olatz, "La identidad musulmana de los mudéjares de la Cuenca del Duero a finales de la Edad Media. Aportaciones desde la aljama de Burgos", Espacio, Tiempo y Forma, Serie III, H. ${ }^{\text {a Medieval, } 27}$ (2014), pp. 525-546.

Arenzana Antoñanzas, Víctor, Los libros de Actas del Concejo de Valladolid (14971520), Tesis Doctoral inédita, Universidad de Valladolid, Valladolid, 2016.

Casassas Canals, Xavier; Villanueva Zubizarreta, Olatz; Tapia Sánchez, Serafín de; Jiménez GadeA, Javier y Echevarría Arsuaga, Ana, De Ávila a La Meca: el relato del viaje de Omar Patún (1491-1495). Serie Historia y Sociedad nº 204, Servicio de Publicaciones de la Universidad de Valladolid, Valladolid, 2017.

FERNÁNDEZ y GONZÁLEZ, Francisco, Estado social y político de los mudéjares de Castilla, Imprenta Joaquín Muñoz, Madrid, 1866.

51 Curiosamente, en el listado de los firmantes que secundaban la reivindicación, aparecen agrupadas o más o menos próximas unas de otras, las rúbricas de un buen número de moriscos, cuyas identidades conocemos por otros padrones de la época (1506 y 1538): en este orden, reconocemos al menos a Diego Ramírez, Antonio Malpartida y Francisco Catalán, Francisco, Gaspar, Luis y Melchor Andado, Beltrán Abanades, Juan de Figueroa, Bernaldino Robles, Juan Malpartida, Francisco Castañón, Francisco de Cisneros, Francisco de Cuéllar, Antonio de Palacios, Francisco Enamorado, Juan de Figueroa, Juan López Enamorado, Juan de Bazán, Fadrique de Palacios, Diego, Álvaro y Francisco Benavides, Íñigo y Francisco de Mendoza, Francisco de Madrid, Diego Alojero, Francisco de Paredes y Juan de Valladolid. A.G.S., PTR, Leg. 70, Doc. 41. 
GonzÁlez Marrero, Ma del Cristo, "Las mujeres de la Casa de Isabel la Católica", Las relaciones discretas entre las monarquias hispana y portuguesa: las Casas de las reinas (siglos XV-XIX), volumen II, José Martínez Millán y $\mathrm{M}^{\mathrm{a}}$ Paula Marçal Lourenço (coords.), Ediciones Polifemo, Madrid, 2008, pp. 841-886.

Ladero Quesada, Miguel Ángel, Los mudéjares de Castilla en tiempos de Isabel I, Instituto Isabel la Católica de Historia Eclesiástica, Valladolid, 1969.

Ladero Quesada, Miguel Ángel, Los mudéjares de Castilla y otros estudios de Historia Medieval andaluza, Universidad de Granada, Granada, 1989.

MoLÉnAT, Jean-Pierre, “À propos d’Abrahen Xarafí: les alcaldes mayores de los moros de Castille au temps des Rois Catholiques", VII Simposio Internacional de Mudejarismo, Instituto de Estudios Turolenses-Centro de Estudios Mudéjares, Teruel, 1999, pp. 175-184.

Moratinos García, Manuel y Villanueva Zubizarreta, Olatz, "Consecuencias del decreto de conversión al cristianismo de 1502 en la aljama mora de Valladolid", Sharq al-Andalus, Revista de Estudios Mudéjares y Moriscos, 16-17 (1999-2002), Homenaje Leonard P. Harvey (2004), pp. 121-144.

Ortego Rico, Pablo, "Cristianos y mudéjares ante la conversión de 1502. Mercedes a moros. Mercedes de bienes de moros", Espacio, Tiempo y Forma, Serie III, H. ${ }^{a}$ Medieval, 24 (2011), pp. 279-318.

Rucquor, Adeline, Valladolid en la Edad Media. El mundo abreviado, Junta de Castilla y León, Valladolid, 1997.

TAPia SÁnchez, Serafín de, "1502 en Castilla La Vieja, de Mudéjares a Moriscos", Edad Media Revista de Historia, 17 (2016), pp. 133-156.

Villanueva ZubizARreta, Olatz, "Vivir y convivir bajo la señal de la media luna: mudéjares y moriscos en Valladolid", Arte mudéjar en la provincia de Valladolid, Diputación Provincial, Valladolid, 2007, pp. 19-33.

Villanueva ZubizarReta, Olatz, "Los moros obligados al fuego" o el primer cuerpo de bomberos de Valladolid", Matafuegos, 500 años de Bomberos en Valladolid. Ayuntamiento de Valladolid, Archivo Municipal de Valladolid e Instituto Universitario de Historia Simancas, Valladolid, 2015, pp. 39-46.

Villanueva Zubizarreta, Olatz, "Los mudéjares del norte de Castilla en vísperas del bautismo: expresiones religiosas de un Islam que no fue al-Ándalus", eHumanistal Conversos, 3 (2015), pp. 194-208.

Villanueva Zubizarreta, Olatz, "Conflictos y arbitrajes en la morería de Valladolid. Entre litigios de la aljama y desavenencias particulares", Minorías en la España medieval y moderna (ss. $X V$ - $X V I I)$, Publications eHumanista, University of California, Santa Bárbara, 2016, pp. 103-115. 